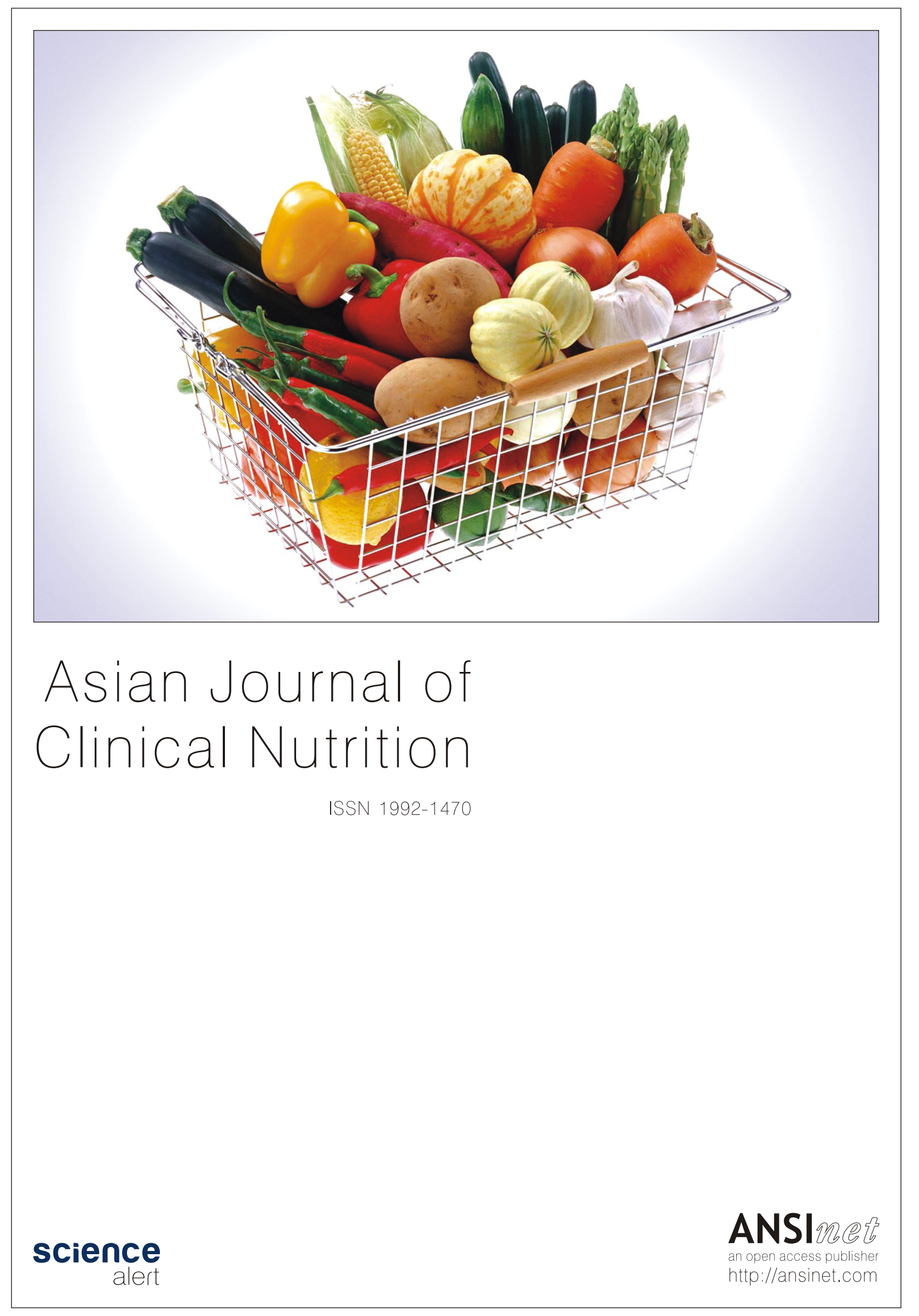




\title{
Research Article \\ Malnutrition and Associated Factors among Children below Five Years of Age Residing in Slum Area of Jaipur City, Rajasthan, India
}

\author{
Pragati Chaudhary and Mukta Agrawal \\ Department of Home Science, University of Rajasthan, Jaipur, India
}

\section{Abstract}

Background and Objective: Children are the foundation of any nation. Children residing in slum areas belong to lower socio-economic strata and live in crowded unhygienic environment. They are vulnerable to malnutrition and associated morbidity and mortality. To assess the prevalence of malnutrition among children aged 6-59 months and its associated socio-demographic factors. Materials and Methods: It was a community based cross-sectional study conducted in year 2016 to 2017 in a slum area of Jaipur city, Rajasthan. A total of 2007 children aged 6-59 months were selected using multistage sampling and were screened using anthropometric measurements such as height, weight and mid upper arm circumference (MUAC). Socio-demographic information was collected using self structured questionnaire. Results: Prevalence of underweight, stunting and wasting was 35.7,43 and 10.5\%, respectively. Malnutrition was found to be associated with socio-demographic factors such as age, caste, family type, birth weight, birth order, educational profile of parents and economic status of family. Utilization of Integrated child development services (ICDS) was found poor. Conclusion: Nutritional status of children under five years of age in the slum area of Jaipur city is not satisfactory. Prevalence of stunting was found high (43\%) as compare to national as well state figure revealed by National Family Health Survey (NFHS-4). More than half of the children (56\%) were born with low birth weight. Services of ICDS is not being utilized properly by target population. Delivery of Anganwadi services needs to be improved.

Key words: Anthropometric measurements, nutritional status, socio-demographic factors, underweight, stunting, wasting

Citation: Pragati Chaudhary and Mukta Agrawal, 2019. Malnutrition and associated factors among children below five years of age residing in slum area of Jaipur City, Rajasthan, India. Asian J. Clin. Nutr., 11: 1-8.

Corresponding Author: Pragati Chaudhary, Department of Home Science, University of Rajasthan, Jaipur, India Tel: 91-7023853353

Copyright: () 2019 Pragati Chaudhary and Mukta Agrawal. This is an open access article distributed under the terms of the creative commons attribution License, which permits unrestricted use, distribution and reproduction in any medium, provided the original author and source are credited.

Competing Interest: The authors have declared that no competing interest exists.

Data Availability: All relevant data are within the paper and its supporting information files. 


\section{INTRODUCTION}

Malnutrition is called as a silent emergency in India'. Malnutrition refers to both under nutrition and over nutrition, which may be in the form of severe nutritional deficiencies to obesity ${ }^{2}$. All over the world nearly 155 million children (22.9\%) are stunted and 52 million children (7.7\%) are wasted ${ }^{3}$. National Family Heath Survey (NFHS-4) results reveal that in India $36 \%$ children are underweight, $38 \%$ are too small for their age and $21 \%$ ate too thin for their height. Rajasthan also reflects similar figure of underweight (36.7\%), stunting (39\%) and wasting (23\%) as reported 4 in NFHS-4.

In developing countries, mortality rate due to malnutrition is about $41 \%$ in the age group of 6-60 months, which accounts for 2.3 million deaths every year ${ }^{5}$. Malnutrition poses a huge threat to the human resources and it needs to be reduced and ultimately eradicated. For this main focus should be on provision of better nutrition.

Improved nutrition is a good platform for health, education and inequality eradication ${ }^{6}$. Adequate nutrition ensures overall health of an individual which includes physical, mental and cognitive development. In addition to all these factors nutrition also helps in proper development of immune system from the very early age. So, it is important to provide proper nutrition right from the birth. Maternal nutrition is as important as a child's nutrition, because a healthy mother gives birth to a healthy child and this eradicates the chances of malnutrition by high margins ${ }^{3}$.

Data on malnutrition is available but malnutrition rates vary from state to state, region to region and from rural to urban areas in India. Early years of life are very vulnerable. The growth is very rapid at this age. The nutritional requirements of various nutrients such as energy, protein, iron, calcium are high. Children fulfill these requirements through breast milk as well as complementary feeding. So, if infant and young child feeding practices are not proper, not giving timely or inappropriate in quantity as well as quality will definitely lead to inadequate nutrition and that further may lead to malnutrition and irreversible changes in nutritional status. Apart from that, unhygienic conditions in the slum area lead to infection. Lack of basic amenities at household level and unhygienic surrounding increase the chances of infection, which contributes to malnutrition among children residing in slum area. Data on malnutrition from slum area of Jaipur city will definitely add on the existing knowledge.

The objective of the study was to assess the prevalence of different grades of malnutrition among children aged 6-59 months and to study its associated socio-demographic factors.

\section{MATERIALS AND METHODS}

Study design: This was a cross sectional community based study.

Study period: Study was conducted from March 2016December, 2017.

Study area and study population: The study was conducted in a slum area of Jaipur city, Rajasthan. There are five ICDS projects in Jaipur Urban, out of which 2 projects (Project II and Project IV) were selected. Two sectors were selected from these selected projects. A total of 22 Anganwadi centers (AWCs) (11 from each selected sector) were chosen as the study area. All the children belonging to the age group of 6-59 months and living in the area of selected AWCs were chosen to form the study population.

Sample size: As per 2011 census of India, there were approximately $11.87 \%$ children less than 5 years of age in the total population of Jaipur city. There is one Anganwadi center for population of 800 children. Every child in this age group residing in the slum area was tried to contact. Overall 2007 children were screened in 22 AWCs.

Sampling technique: Multistage sampling was used to select 2007 children under 5 years of age. Projects and sectors were selected through convenience sampling and Anganwadi centers were selected by using cluster sampling.

Inclusion criteria: All the children in the age group of 6-59 months and living in the coverage area of selected Anganwadi centers.

Exclusion criteria: Children who were terminally ill, suffering from genetic diseases, mentally retarded and having cardiac problems were excluded from the study.

Data collection: Ethical approval was taken from the Departmental Ethical Committee before the commencement of the research work. A questionnaire was prepared to collect the data on the socio-demographic profile of children such as the name of child, age, sex, religion, caste, mother's name, father's name, family type, birth weight, birth order, number of siblings, educational status of parents, monthly family income, per capita income and utilization of services provided at AWC under ICDS programme. Nutritional status was assessed according to WHO weight-for-age, height-for-age, 
weight-for-height reference chart. Underweight, stunting and wasting were defined as z-score $<-2$ SD from the median WHO child growth standards. Severe underweight, stunting and wasting were defined as z-score $<-3$ SD from the median WHO child growth standards $s^{7-10}$.

Study tools and techniques: Pre-structured questionnaire was used to assess the socio-demographic profile of study subjects and utilization of ICDS services.

Age assessment was done by using anganwadi records, immunization card, Mamta card, delivery card. Event calendar was used for those children whose record was not found by any of the aforementioned records. Birth weight was recorded from Mamta card, mother and child protection card and delivery card. Anthropometric parameters such as age, weight, height and MUAC were recorded using standard tools and techniques. Weight was recorded using digital baby and toddler weighing scale with minimum and maximum weighing capacity of $5 \mathrm{~g}$ and $30 \mathrm{~kg}$, respectively. Weight was recorded in kilograms and grams. Length was recorded for children less than 2 years of age and for children who were not able to stand properly, by using Prestige height length measuring board having graduation from $1 \mathrm{~mm}$. Height of children more than 2 years of age was recorded using Prestige portable stadiometer with graduation from $1 \mathrm{~mm}$. The MUAC was recorded using tri-color strips. All the tools were procured from UNICEF Rajasthan Field office, Jaipur. Descriptive statistics such as frequencies and percentages were used for univariate variables. Chi-square test was used to assess the association of malnutrition with study variables.

Data analysis: Descriptive statistics such as frequencies and percentage were used for univariate variables. Chi-square test was used to assess the association of malnutrition with study variables at 5 and $1 \%$ level of significance.

\section{RESULTS}

Socio-demographic profile of children: Among 2007 children, 926 (46.1\%) children were from the age group of 12-35 months and 857 (42.7\%) from the age group of 36-59 months of age, remaining were in the age group of 6-12 months. There were almost equal number of boys (49.5\%) and girls (50.4\%). Children were mostly from the Hindu community (83.3\%). Majority of children were from nuclear family $(55.1 \%)$ and having $<2$ siblings $(62.8 \%)$. Half of the children were born on 2nd or 3rd birth order (51.8\%). Difference between two pregnancies for $<24$ months was reported by $72.7 \%$ mothers. Around $43 \%$ mothers were illiterate and only $18.4 \%$ were educated till primary level. While remaining $38 \%$ by took education till senior secondary level and higher education. One fourth of fathers were illiterate while $53 \%$ were educated upto secondary level.

Utilization of ICDS services: Registration of children at AWCS was found low i.e., only $63.6 \%$ children were registered at the AWCs. The percentage of children below 3 years of age availing the facility of Take Home Ration (THR) was only $68 \%$. Frequency of collecting THR was also found very poor. Mothers were not regularly collecting THR every week. They used to skip one-two week in between. Utilization of THR was very low (only $1 \%$ ). Only $77 \%$ of registered children were regularly weighed. Most of the children (88.6\%) were immunized. Children who were not immunized were more underweight (51.9\%), stunted (55.0\%) and wasted (18.0\%) comparing to the children who were immunized.

Prevalence of malnutrition among under five children: Out of total 2007 children screened, $35.7 \%$ were found underweight, $43 \%$ were stunted and $10.5 \%$ were wasted. Moderate acute wasting was found among $8.0 \%$ children while severe acute wasting was found among $2.5 \%$ children (Fig. 1). More than half of the children were born with low birth weight (56.5\%).

Association of malnutrition with socio-demographic factors: Social determinants such as age of child, caste, number of siblings child has, birth order, birth weight, education status of the parents and economic status of the family were positively associated with underweight and stunting, whereas wasting was not associated with birth order of the child. There was no significant association between gender, religion, type of the family and household family size with malnutrition (Table 1).

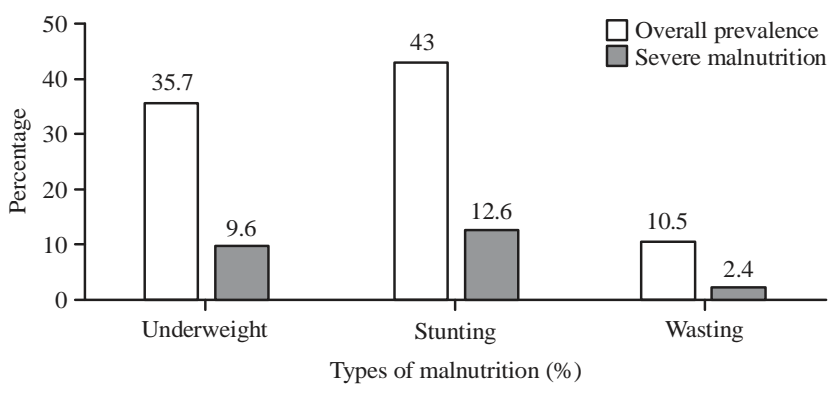

Fig. 1: Prevalence of different types of malnutrition among under 5 children 
Asian J. Clin. Nutr., 11 (1): 1-8, 2019

Table 1: Percentage of distribution of malnourished children according to various socio-demographic parameters

\begin{tabular}{|c|c|c|c|c|c|c|}
\hline \multirow[b]{2}{*}{ Variables } & \multicolumn{6}{|c|}{ Different types of malnutrition } \\
\hline & Underweight $<-2$ SD & Chi-square (p-value) & Stunting $<-2$ SD & Chi-square (p-value) & Wasting $<-2$ SD & Chi-square (p-value) \\
\hline \multicolumn{7}{|l|}{ Age } \\
\hline 6-11 months $(<1$ year) $(\mathrm{N}=224)$ & $60(26.7 \%)$ & $20.048(0.003)^{* *}$ & $73(32.5 \%)$ & $26.214(0.000)^{* *}$ & $20(8.9 \%)$ & $30.885(0.000)^{* *}$ \\
\hline $12-35$ months ( $1-3$ years) $(\mathrm{N}=926)$ & $341(36.8 \%)$ & & $428(46.2 \%)$ & & $105(11.3 \%)$ & \\
\hline $36-60$ months ( $3-5$ years) $(N=857)$ & $316(36.8 \%)$ & & $363(42.3 \%)$ & & $86(10.0 \%)$ & \\
\hline \multicolumn{7}{|l|}{ Gender } \\
\hline Female $(\mathrm{N}=1012)$ & $354(34.9 \%)$ & $0.594(0.898)^{\mathrm{NS}}$ & $414(40.9 \%)$ & $5.036(0.169)^{\mathrm{NS}}$ & $95(9.3 \%)$ & $3.611(0.307)^{\mathrm{NS}}$ \\
\hline Male $(\mathrm{N}=995)$ & $363(36.4)$ & & $450(45.2 \%)$ & & $116(11.6 \%)$ & \\
\hline \multicolumn{7}{|l|}{ Religion } \\
\hline Hindu $(N=1672)$ & $611(36.5 \%)$ & $8.237(0.221)^{\mathrm{NS}}$ & $725(43.3 \%)$ & $3.970(0.681)^{\mathrm{NS}}$ & $182(10.8 \%)$ & $12.131(0.059)^{\mathrm{NS}}$ \\
\hline Muslim (N = 329) & $105(31.9 \%)$ & & $138(41.9 \%)$ & & $28(8.5 \%)$ & \\
\hline Sikh $(N=6)$ & $1(16.6 \%)$ & & $1(16.6 \%)$ & & $1(16.6 \%)$ & \\
\hline \multicolumn{7}{|l|}{ Caste } \\
\hline General (N = 243) & $73(30.0 \%)$ & $29.649(0.003)^{* *}$ & 89 (36.6\%) & $23.366(0.025)^{*}$ & $21(8.6 \%)$ & $24.823(0.016)^{*}$ \\
\hline $\mathrm{OBC}(\mathrm{N}=358)$ & $107(29.8 \%)$ & & $145(40.5 \%)$ & & $32(8.9 \%)$ & \\
\hline $\mathrm{SC}(\mathrm{N}=1002)$ & $410(40.9 \%)$ & & $465(46.4 \%)$ & & $125(12.4 \%)$ & \\
\hline $\mathrm{ST}(\mathrm{N}=72)$ & $21(29.1 \%)$ & & $26(36.1 \%)$ & & $5(6.9 \%)$ & \\
\hline Minority $(N=332)$ & $106(31.9 \%)$ & & $139(41.8 \%)$ & & $28(8.4 \%)$ & \\
\hline \multicolumn{7}{|l|}{ Family type } \\
\hline Nuclear $(\mathrm{N}=1106)$ & $401(36.2 \%)$ & $4.546(0.603)^{\mathrm{NS}}$ & $481(43.4 \%)$ & $7.611(0.268)^{\mathrm{NS}}$ & $113(10.2 \%)$ & $4.560(0.601)^{\mathrm{NS}}$ \\
\hline Joint $(\mathrm{N}=901)$ & $316(35.0 \%)$ & & $383(42.5 \%)$ & & $98(10.8 \%)$ & \\
\hline \multicolumn{7}{|l|}{ Number of siblings } \\
\hline$<2(N=1261)$ & $417(33.0 \%)$ & $17.234(0.008)^{* *}$ & $508(40.2 \%)$ & $16.782(0.010)^{*}$ & $125(9.9 \%)$ & $7.556(0.272)^{\mathrm{NS}}$ \\
\hline $2-4(N=711)$ & $283(39.8 \%)$ & & $336(47.2 \%)$ & & $83(11.6 \%)$ & \\
\hline$>4(\mathrm{~N}=35)$ & $17(48.5 \%)$ & & 20 (57.1\%) & & $3(8.5 \%)$ & \\
\hline \multicolumn{7}{|l|}{ Birth order of the child } \\
\hline $1(\mathrm{~N}=785)$ & $263(33.5 \%)$ & $21.397(0.011)^{*}$ & $313(39.8 \%)$ & $17.492(0.042)^{*}$ & $68(8.6 \%)$ & $13.473(0.142)^{\mathrm{NS}}$ \\
\hline $2-3(N=1040)$ & $368(35.3 \%)$ & & $454(43.6 \%)$ & & $117(11.2 \%)$ & \\
\hline $4-5(N=157)$ & $73(46.4 \%)$ & & $81(51.5 \%)$ & & $25(15.9 \%)$ & \\
\hline $6-8(N=23)$ & $12(52.1)$ & & $15(65.2 \%)$ & & $1(4.3 \%)$ & \\
\hline $9-10(N=1)$ & $0(0.0 \%)$ & & $1(100.0 \%)$ & & $0(0.0 \%)$ & \\
\hline $11-12(\mathrm{~N}=1)$ & $1(100.0 \%)$ & & $0(0.0 \%)$ & & $0(0.0 \%)$ & \\
\hline \multicolumn{7}{|l|}{ Birth weight (kg) } \\
\hline$\leq 2.5 \mathrm{~kg}(\mathrm{~N}=1135)$ & $543(47.8 \%)$ & $208.819(0.000)^{*}$ & $612(53.9 \%)$ & $161.158(0.000)^{* *}$ & $170(14.9 \%)$ & $86.432(0.000)^{* *}$ \\
\hline $2.5-3.5 \mathrm{~kg}(\mathrm{~N}=843)$ & $170(20.1 \%)$ & & $250(29.6 \%)$ & & $39(4.6 \%)$ & \\
\hline$>3.5(\mathrm{~N}=28)$ & $4(14.2 \%)$ & & $2(7.1 \%)$ & & $2(7.1 \%)$ & \\
\hline \multicolumn{7}{|l|}{ Educational status of mother } \\
\hline Illiterate $(N=863)$ & $357(41.3 \%)$ & $55.350(0.000)^{* *}$ & $421(48.7 \%)$ & $30.341(0.000)^{* *}$ & $108(12.5 \%)$ & $28.057(0.001)^{* *}$ \\
\hline Primary (upto 5 th) $(\mathrm{N}=371)$ & $126(33.9 \%)$ & & $154(41.5 \%)$ & & $34(9.1 \%)$ & \\
\hline Secondary (5th-12th) $(N=710)$ & $217(30.5 \%)$ & & $272(38.3 \%)$ & & $61(8.5 \%)$ & \\
\hline Higher (above 12th) $(\mathrm{N}=63)$ & $17(26.9 \%)$ & & $17(26.9 \%)$ & & $8(12.6 \%)$ & \\
\hline \multicolumn{7}{|l|}{ Educational status of father } \\
\hline Illiterate $(\mathrm{N}=504)$ & $212(42.0 \%)$ & $35.831(0.000)^{* *}$ & $259(51.3 \%)$ & $24.198(0.004)^{* *}$ & $68(13.4 \%)$ & $21.559(0.010)^{*}$ \\
\hline Primary (upto 5th) $(\mathrm{N}=278)$ & $96(34.5 \%)$ & & $117(42.0 \%)$ & & $25(8.9 \%)$ & \\
\hline Secondary (5th-12th) $(N=1083)$ & $367(33.8 \%)$ & & $444(40.9 \%)$ & & $107(9.8 \%)$ & \\
\hline Higher (above 12th) $(\mathrm{N}=143)$ & $42(29.3 \%)$ & & $49(34.2 \%)$ & & $11(7.6 \%)$ & \\
\hline \multicolumn{7}{|l|}{ Monthly family income } \\
\hline$<5000(N=176)$ & $82(46.5 \%)$ & $24.514(0.000)^{* *}$ & $97(55.1 \%)$ & $18.496(0.005)^{* *}$ & $25(14.2 \%)$ & $23.218(0.001)^{* *}$ \\
\hline $5000-10000(\mathrm{~N}=1388)$ & $502(36.1 \%)$ & & 602 (43.3\%) & & $157(11.3 \%)$ & \\
\hline$>1000(N=443)$ & 133 (30.0\%) & & 165 (37.2\%) & & $29(6.5 \%)$ & \\
\hline \multicolumn{7}{|l|}{ Per capita/per person/per month } \\
\hline $100-500(N=77)$ & $37(48.0 \%)$ & $17.210(0.009)^{* *}$ & $42(54.5 \%)$ & $19.097(0.004)^{* *}$ & $9(11.6 \%)$ & $37.694(0.000)^{* *}$ \\
\hline $501-1000(N=569)$ & $228(40.0 \%)$ & & $269(47.2 \%)$ & & $78(13.7 \%)$ & \\
\hline$>1000(\mathrm{~N}=1361)$ & $452(33.2 \%)$ & & $553(40.6 \%)$ & & $124(9.1 \%)$ & \\
\hline \multicolumn{7}{|l|}{ Household family size } \\
\hline Five or less $(\mathrm{N}=1095)$ & $384(35.0 \%)$ & $1.280(0.734)^{N S}$ & $468(42.7 \%)$ & $7.558(0.056)^{\mathrm{NS}}$ & 109 (9.9\%) & $4.561(0.207)^{\mathrm{NS}}$ \\
\hline More than five $(\mathrm{N}=912)$ & $333(36.5 \%)$ & & $396(43.4 \%)$ & & $102(11.1 \%)$ & \\
\hline How long residing in Jaipur & & & & & & \\
\hline$<5$ years $(N=168)$ & 74 (44.0\%) & $12.851(0.045)^{*}$ & 94 (55.9\%) & $18.068(0.006)^{* *}$ & 21 (17.8\%) & $10.564(0.103)^{\mathrm{NS}}$ \\
\hline $5-10$ years $(N=488)$ & $177(36.2 \%)$ & & $222(45.4 \%)$ & & $54(11.0 \%)$ & \\
\hline$>10$ years $(\mathrm{N}=1351)$ & $466(34.4 \%)$ & & $548(40.6 \%)$ & & $136(10.0 \%)$ & \\
\hline
\end{tabular}


Asian J. Clin. Nutr., 11 (1): 1-8, 2019

Table 2: Distribution (\%) of malnourished children according to utilization of ICDS services

\begin{tabular}{|c|c|c|c|c|c|c|}
\hline \multirow[b]{2}{*}{ Variables } & \multicolumn{6}{|c|}{ Different types of malnutrition } \\
\hline & Underweight $<-2$ SD & Chi-square (p-value) & Stunting $<-2$ SD & Chi-square (p-value) & Wasting $<-2$ SD & Chi-square ( $p$-value) \\
\hline \multicolumn{7}{|l|}{ Registered at AWC } \\
\hline Yes $(N=1277)$ & $444(34.7 \%)$ & $1.607(0.658)^{\mathrm{NS}}$ & $555(43.4 \%)$ & $0.534(0.911)^{\mathrm{NS}}$ & $123(43.4 \%)$ & $6.922(0.074)^{\mathrm{NS}}$ \\
\hline No $(N=730)$ & $273(37.3 \%)$ & & $309(42.3 \%)$ & & $88(42.3 \%)$ & \\
\hline \multicolumn{7}{|l|}{ Collect THR } \\
\hline Yes $(N=367)$ & $135(36.7 \%)$ & $2.547(0.467)^{\mathrm{NS}}$ & $160(43.5 \%)$ & $5.434(0.143)^{\mathrm{NS}}$ & $40(10.8 \%)$ & $1.326(0.723)^{\mathrm{NS}}$ \\
\hline No $(N=783)$ & $265(33.8 \%)$ & & $341(43.5 \%)$ & & $84(10.7 \%)$ & \\
\hline \multicolumn{7}{|l|}{ Regularly weighed } \\
\hline Yes $(N=1563)$ & $400(25.5 \%)$ & $329.537(0.000)^{* *}$ & $517(33.0 \%)$ & $293.151(0.000)^{* *}$ & $134(8.5 \%)$ & $64.995(0.000)^{* *}$ \\
\hline No $(\mathrm{N}=444)$ & $317(71.3 \%)$ & & $347(78.1 \%)$ & & $77(17.3 \%)$ & \\
\hline \multicolumn{7}{|l|}{ Immunization status } \\
\hline Immunized $(n=1780)$ & $599(33.6 \%)$ & $30.597(0.000)^{* *}$ & $739(41.5 \%)$ & $18.981(0.000)^{* *}$ & $170(9.5 \%)$ & $28.598(0.000)^{* *}$ \\
\hline Not immunized ( $n=227$ ) & $118(51.9 \%)$ & & $125(55.0 \%)$ & & $41(18.0 \%)$ & \\
\hline
\end{tabular}

NS: Non significant, ${ }^{*}$ Significant at $5 \%,{ }^{*}$ Significant at $1 \%$

Association of malnutrition with utilization of ICDS services: Children with all three types of malnutrition showed statistically significant association with growth monitoring and immunization status. Malnutrition was found significantly higher among children who did not undergo regular growth monitoring and who were not immunized. Registration of children at AWCs and collection of THR were not found significantly associated with underweight, stunting as well wasting (Table 2).

\section{DISCUSSION}

Present study was done to assess the prevalence of different grades of malnutrition and their association with socio-demographic factors and utilization of ICDS services. In present study, high prevalence of malnutrition was reported. Results of the present study revealed that prevalence of underweight, stunting and wasting was 35.7, 43.0 and $10.5 \%$, respectively. In addition with the previous researches, findings of the present study also concluded that prevalence of stunting was very high, which represents the most common form of malnutrition followed by underweight and wasting.

The prevalence of underweight is a composite indicator of overall malnutrition. It is an outcome of both chronic as well as acute malnutrition. Overall prevalence of underweight was found $35.7 \%$. The percentage of moderately and severely underweight children was 26.1 and 9.6\%, respectively. Percentage of underweight reported in the present study was almost similar to the NFHS-4 data for India (36\%) and for Rajasthan (36.7\%), whereas higher than the data reported for Jaipur city $(25.2 \%)^{4}$. Underweight as reported in many studies was much higher than present study findings ${ }^{11-15}$. While other studies reported lower prevalence of underweight as compared to present study findings ${ }^{16-17}$.

The prevalence of stunting is the indicator of short height for age and an outcome of chronic malnutrition. High prevalence of stunting was observed in children as $43 \%$ children were stunted. Prevalence of moderate and severe stunting were 30.3 and $12.6 \%$, respectively. The percentage of stunted children found in the present study was much higher than NFHS-4 data i.e., 38\% for India, 39\% for Rajasthan and $35.7 \%$ for Jaipur city ${ }^{4}$. Higher prevalence of stunting was reported by many authors ${ }^{6,10}$, whereas some authors reported lower prevalence of stunting as compared to the present study ${ }^{13,15-16,18}$. Singh et al. ${ }^{12}$ reported comparable results (43.22\%).

Wasting is the result of acute malnutrition and describes current nutritional status. Wasting was found among $10.5 \%$ children, from which $8.0 \%$ were moderately wasted and $2.4 \%$ having severe wasting. The percentage of children suffering from wasting was much lower than NFHS-4 data i.e., $21 \%$ in India and $23 \%$ in Rajasthan but near to the Jaipur city data on wasting ${ }^{4}$ i.e., $12.8 \%$. As compared to prevalence shown in present study, higher prevalence of wasting was reported in many studies ${ }^{11-16,18}$.

Age was found significantly associated with malnutrition. Malnutrition was highest among 1-3 years of age group. Similar to the findings of the present study, Sethy et al. ${ }^{15}$ reported that underweight was more prevalent in the age group of 36-60 months, whereas prevalence of wasting was more among age group of 37-48 months. Many studies reported that as the age of the child increases the chances of being underweight also increases $13,14,19$. 
Gender wise discrepancy in prevalence of underweight, stunting and wasting was not found as there was no significant difference in the prevalence among boys and girls.

More Hindu children were malnourished as compared to children belonging to other religious communities. The percentage of malnourished children were calculated from their own total numbers. But the association of religion with underweight, stunting and wasting was not found significant.

Caste was also significantly associated with malnutrition as prevalence of underweight, stunting and wasting was found highest in children belonging to schedule caste followed by Minority and OBC community. Similar results were reported by Tiwari et al. ${ }^{20}$.

Underweight and stunting was significantly associated with number of siblings child has, but results for wasting were not significant. Whereas Mushtaq et al. ${ }^{21}$ reported that stunting and wasting were significantly associated with greater number of siblings.

As birth order increases, prevalence of underweight and stunting was also found to be increasing, wasting was more among children born at birth order 2-3 and results were statistically significant. Tiwari et al. ${ }^{20}$ and Shankar ${ }^{22}$ supported the findings of the present study that children born at higher birth order were more malnourished and found to be associated with underweight and stunting. Association with wasting was not found very significant.

In support of the present study some studies showed that birth size is significantly associated to child's nutritional status $^{21}$. Children born with normal weight at birth had less chances of being underweight, stunted and wasted ${ }^{14}$.

Children of uneducated or less educated parents were more malnourished as compared to those having educated parents. Findings were supported by many researchers ${ }^{13-14,17,20,22}$. Mother's education was found as an important factor for better nutritional status of children. Prevalence of stunting and wasting was found higher in children whose mothers were either illiterate or less educated; supportive findings were reported by Kavoski et al..$^{23}$ and Achakzai and Khan ${ }^{19}$. Educational level of father is more important in developing countries because of the fact of male dominance in the family economy ${ }^{17}$. Significant association between father's education and child malnutrition found in present study was supported by other studies also ${ }^{21-23}$. In contrary to the present study some studies have shown no significant association between child malnutrition and father's education ${ }^{24-25}$. Household monthly family income or wealth status affects the purchasing power. Poor purchasing power was found to be associated with malnutrition; supported by other studies $16,22,20-27$.
Results on utilization of ICDS services showed that registration at Anganwadi centers is an indicator of utilization of ICDS services. Underweight was found higher among children who were not registered at Anganwadi centers. No significant association was found in prevalence of stunting as well as wasting and registration of children at AWCs. It was observed that utilization of supplementary nutrition service of ICDS programme was not satisfactory (Table 2). This may be a reason for having no association between underweight, stunting and wasting with take home ration.

Growth monitoring was found to be a great influencing factor which helps in early detection of children with malnutrition and was found significantly associated with malnutrition. Children who were regularly weighed were better nourished than those who were not regularly weighed. Immunization also affects the nutritional status of children, Children who have received full immunization have less chances to get infected, which further affect their nutritional status. It was observed that malnutrition of all three types was higher among children who were not fully immunized. Findings of the study done by Sarkar ${ }^{22}$ also supported the result of the present study that nutritional status of children is affected by immunization status.

It was observed that many children were not registered at AWCs because in a slum dwelling every time newly migrating families keep coming are being added to the population. These recently migrated population were not registered at AWCs. The present study did not find any significant association with all three types of malnutrition and registration of children at AWCs. The percentage of registered children was only $63 \%$.

Utilization of THR was not significantly associated with malnutrition. The THR was not collected by $68 \%$ of children. Only $32 \%$ were availing THR. Only $1 \%$ children were given THR daily. While the frequency of feeding THR was not according to the recommendations. This indicated that the counselling to mothers regarding availing of THR was not adequately provided by Anganwadi workers or Asha sahayogini. The mothers are not counseled properly to give THR to children daily. That is why the facility is not being utilized properly. There is a need of prompt counseling by ASHA sahayogini and Anganwadi worker along with the proper supply of THR to more children.

\section{CONCLUSION}

The nutritional status of preschool children residing in slum area of Jaipur city was not found satisfactory and the prevalence of stunting was higher than National, Rajasthan as 
well as Jaipur city data (NFHS-4). The determinants of malnutrition includes age, caste, number of siblings child has birth order of the child, birth weight, educational and economic status of the parents, poor growth monitoring and low vaccination status of the children. Utilization of ICDS services was found poor which further reflects on the nutritional status of children. There is need to improve the delivery of Anganwadi services, strengthening the nutrition education session and counselling the mothers for proper utilization of THR to prevent stunting and wasting.

\section{SIGNIFICANCE STATEMENT}

This study discovered that higher number of children residing in the slum area of Jaipur city are short for their age. Services of ICDS is not being delivered properly which reflects through the poor nutritional status of children. These findings can be beneficial for the policy makers, so that proper surveillance of ICDS services can be done to make aware and motivate the population to utilize these services properly. This study will help the researcher to uncover the critical areas of the nutritional status and determinants of malnutrition in slum area of Jaipur city along with how ICDS services is being utilized by the target population. Thus a new theory on proper functioning of ICDS services may be arrived.

\section{REFERENCES}

1. USAID India, 2017. Child and maternal nutrition in India. Factsheet, American People through the United States Agency for International Development (USAID), India. https://pdf.usaid.gov/pdf_docs/Pnadm627.pdf

2. Kandala, N.B., T.P. Madungu, J.B. Emina, K.P. Nzita and F.P. Cappuccio, 2011. Malnutrition among children under the age of five in the Democratic Republic of Congo (DRC): Does geographic location matter? BMC Public Health, Vol. 11. 10.1186/1471-2458-11-261.

3. UNICEF., WHO. and World Bank Group-Joint Child Malnutrition Estimates, 2017. Levels and trends in child malnutrition: Key findings of the 2017 edition. UNICEF., WHO. and The World Bank Group, Washington DC., pp: 1-15.

4. International Institute for Population Sciences, 2016. National family health survey 4: India fact sheet 2015-16. International Institute for Population Sciences, Deemed University, Mumbai, India, pp: 1-6.

5. Sahu, S.K., S.G. Kumar, B.V. Bhat, K.C. Premarajan, S. Sarkar, G. Roy and N. Joseph, 2015. Malnutrition among under-five children in India and strategies for control. J. Nat. Sci. Biol. Med., 6: 18-23.
6. IFPRI., 2016. Global Nutrition Report: From Promise to Impact, Ending Malnutrition by 2030. International Food Policy Research Institute, Washington, D.C., pp: 1-112.

7. WHO., 2008. Training course on child growth assessment: WHO child growth standards, A-introduction. http://whqlibdoc.who.int/publications/2008/97892415950 70_A_eng.pdf

8. WHO., 2006. WHO Child Growth Standards: Length/Heightfor-Age, Weight-for-Age, Weight-for-Length, Weightforheight and Body Mass Index-for-Age: Methods and Development. WHO Press, Geneva, Switzerland, ISBN: 92-4154693-X, Pages: 312.

9. WHO. and UNICEF., 2009. WHO child growth standards and the identification of severe acute malnutrition in infants and children. World Health Organization (WHO) and The United Nations Children's Fund (UNICEF), Geneva, Switzerland.

10. ACF International, 2010. Taking action nutrition for survival, growth and development. White Paper-May 2010. https://www.who.int/pmnch/topics/child/acf_whitepaper. pdf

11. Yadav, S.S., S.T. Yadav, P. Mishra, A. Mittal, R. Kumar and J. Singh, 2016. An epidemiological study of malnutrition among under five children of rural and urban Haryana. J. Clin. Diagn. Res., 10: LC07-LC10.

12. Singh, J.P., S.B. Gupta, V.P. Shrotriya and P.N. Singh, 2013. Study of nutritional status among under five children attending out patient department at a primary care rural hospital, Bareilly (UP). Schol. J. Applied Med. Sci., 1: 769-773.

13. Shahjada, A., B.K. Sharma, S. Sharma, P. Mahashabde and A. Bachhotiya, 2014. Effects of birth interval on nutritional status of under five children in periurban area of Madhya Pradesh, India. Int. J. Med Sci. Public Health, 3: 723-726.

14. Manjunath, R., J.K. Kumar, P. Kulkarni, K. Begum and M.R. Gangadhar, 2014. Malnutrition among under-five children of kadukuruba tribe: Need to reach the unreached. J. Clin. Diagn. Res., 8: JC01-JCO4.

15. Sethy, S.G., D. Jena, P. Jena, S. Pradhan and T. Biswas, 2017. Prevalence of malnutrition among under five children of urban slums of Berhampur, Odisha, India: A community a community based cross-sectional study. Int. J. Contemp. Pediatr., 4: 2180-2186.

16. Mgongo, M., N.A. Chotta, T.H. Hashim, J.G. Uriyo and D.J. Damian et al., 2017. Underweight, stunting and wasting among children in Kilimanjaro region, Tanzania; A population-based cross-sectional study. Int. J. Environ. Res. Public Health, Vol. 14. 10.3390/ijerph14050509.

17. Reddy, V.B., Y.S. Kusuma, C.S. Pandav, A.K. Goswami and A. Krishan, 2016. Prevalence of malnutrition, diarrhea and acute respiratory infections among under-five children of Sugali tribe of Chittoor district, Andhra Pradesh, India. J. Nat. Sci. Biol. Med., 7: 155-160. 
18. Kizilyildiz, B.S., B. Sonmez, K. Karaman, B. Beger, A. Mercen, S. Alioglu and Y. Cesur, 2016. Prevalence, demographic characteristics and associated risk factors of malnutrition among 0-5 aged children: A cross-sectional study from Van, Eastern Turkey. Pediatr. Rep., Vol. 8. 10.4081/pr.2016.6112.

19. Achakzai, P. and R. Khan, 2016. Nutritional status and associated factors among children less than five years of age in Tehsil Zarghoon Town, District Quetta, Baluchistan. J. Ayub Med. Coll. Abbottabad-Pak., 28: 146-151.

20. Tiwari, S.R., J.R. Bandi, S.R. Awasthi and A.A. Sharma, 2016. Assessment of prevalence of protein energy malnutrition in under 5 year children in an urban slum of Mumbai, India and to study associated factors. Int. J. Community Med. Public Health, 3: 1129-1134.

21. Mushtaq, M.U., S. Gull, U. Khurshid, U. Shahid, M.A. Shad and A.M. Siddiqui, 2011. Prevalence and socio-demographic correlates of stunting and thinness among Pakistani primary school children. BMC Public Health, Vol. 11. 10.1186/14712458-11-790.

22. Sarkar, S., 2016. Cross-sectional study of child malnutrition and associated risk factors among children aged under five in West Bengal, India. Int. J. Popul. Stud., 2: 89-102.
23. Kavosi, E., Z.H. Rostami, A. Nasihatkon, M. Moghadami and M. Heidari, 2014. Prevalence and determinants of under-nutrition among children under six: A cross-sectional survey in Fars province, Iran. Int. J. Health Policy Manage., 3: 71-76.

24. Keino, S., P. Guy, E. Grace and B.V.D. Borne, 2014. Determinants of stunting and overweight among young children and adolescents in Sub-Saharan Africa. Food Nutr. Bull., 35: 167-178.

25. Endris, N., H. Asefa and L. Dube, 2017. Prevalence of malnutrition and associated factors among children in rural Ethiopia. BioMed Res. Int., Vol. 2017. 10.1155/2017/6587853.

26. Upadhyay, R.P., P. Chinnakali, M. Bhilwar, B. Krishnan, V. Kulkarni, A. Gupta and S.A. Rizwan, 2017. Prevalence of malnutrition, acute respiratory infections and diarrhoea in children aged 1-5 years in urban slums of Puducherry, South India. Int. J. Contemp. Pediatr., 2: 37-41.

27. Yalew, B.M., 2014. Prevalence of malnutrition and associated factors among children age 6-59 months at Lalibela town administration, North Wollo Zone, Anrs, Northern Ethiopia. J. Nutr. Disord. Ther., Vol. 4, No. 1. 10.4172/2161-0509.1000132. 